\title{
The Natural and Infrastructural Capital Elements of Potential Post-Electrification Wealth Creation in Kenya
}

\author{
Diego Ponce de Leon Barido \\ University of California Berkeley \\ Berkeley, California, USA \\ diego.leon@berkeley.edu
}

\author{
Simone Fobi Nsutezo \\ Columbia University \\ New York, New York, USA \\ sf2786@columbia.edu
}

\author{
Jay Taneja \\ University of Massachusetts Amherst \\ Amherst, Massachusetts, USA \\ jtaneja@umass.edu
}

\begin{abstract}
While it is widely accepted that electricity is a "necessary but not sufficient condition" for development, there is little research that explores the conditions under which electrification might lead to wealth creation post-electrification. Using Kenya as a case study, this paper uses natural capital (NC) and infrastructural capital (IC) to compare the enabling environments of entrepreneur vs. government run off-grid electrification projects, explores the role that $\mathrm{NC}$ and IC can play in determining wealth creation post-electrification, and develops a microenterprise development (MED) index indicating regions in Kenya that could be well positioned for wealth creation (and thus, persistent demand) post-electrification. A comparison between the MED index and a nightlights GDP per capita proxy finds that their local differences are informative towards the management and use of local resources, suggests that a nightlights proxy could provide a large underestimate, and sheds light towards regions where the gap between achieved and unrealized potential may be large. We hypothesize that the large discrepancy between our MED index and the nightlights income proxy is due to an underestimate of economic activity by nightlights (most of the economic activity in rural areas happens during the day), the nature of the MED index being a measure of 'potential', and several other factors that could affect both variables such as local climate and environmental conditions, population stress on natural resources, quality of infrastructural capital (not only access), local corruption, and ethnic favoritism. We discuss these at length throughout our paper.
\end{abstract}

Keywords: energy access; entrepreneurship; renewable energy; development; sustainability; natural capital; infrastructure

\section{Introduction}

There are currently many ongoing efforts that are working towards enabling off-grid electricity access for over 1.2 billion people across the world. These efforts range from institutional initiatives like the United Nations Sustainable Energy for All Initiative, the Power Africa program from the United States Agency for International Development, to philanthropy like the Gates and Vulcan foundations, and entrepreneurial efforts as exemplified by solar home system and microgrid entrepreneurs like M-KOPA Solar, Powerhive, and PowerGen, in Kenya and Tanzania.

While the traditional approach of providing electricity access via a centralized transmission grid is regarded by some as inefficient (e.g., insufficient energy service and reliability, extended building times and construction challenges to connect remote areas), offgrid solutions also present numerous challenges including lowcost recovery, poor operations and management, schedule nonadherence and poor tariff collection [1][2]. Both the centralized approach and the decentralized approach have inefficiencies, and both have virtuous cycles that can be galvanized to provide long lasting and sustainable energy solutions to households, businesses, villages, and towns without electricity access [1]. In many countries and regions across the world including Latin America, East Asia, Sub-Saharan Africa, and large parts of India, the centralized electricity access approach has had decades to achieve its goals, and yet, millions of households and businesses around the world remain unconnected [2].

The case study of Kenya is particularly insightful as the rapid spread of off-grid systems demonstrates cost-effective and climate beneficial solutions for an unmet need [2], and also suggests that energy poverty exists in areas with decades of legacy electricity infrastructure, where households can remain without access despite the grid literally passing over their rooftops [3]. This paper does not debate the benefits of electrification via a traditional centralized approach (transmission grid) vs. decentralized off-grid solutions such (pico-power, solar home systems, and microgrids), but rather explores the conditions under which electrification can lead to long term sustainability and socially beneficial outcomes. Despite the widely accepted notion that electricity is "a necessary but not sufficient condition" for development, there is very little research that explores electrification beyond the household, and the conditions under which wealth creation can occur, human development outcomes can improve, and small businesses and micro-entrepreneurs can flourish.

This papers attempts to fill this gap and argues that natural capital (NC) and infrastructural capital (IC) play a crucial role in determining sustained electricity demand and socially beneficial outcomes after initial electrification. Using spatial analysis of NC and IC data, this paper explores the enabling environments of entrepreneur vs. government run off-grid electrification projects, explores the role that $\mathrm{NC}$ and IC can play in determining wealth creation post-electrification, and develops a micro-enterprise development potential index, indicating areas in Kenya where $\mathrm{NC}$ and IC could be well positioned for communities to derive a panoply of social co-benefits after initial electrification. We aggregate NC and IC publicly available data at the smallest administrative unit possible in Kenya (ward level), normalize and scale all features, and construct a non-weighted micro-enterprise development (MED) potential index. We use the MED index to spatially explore regions in Kenya with high potential for microenterprise development after first electrification. To understand how the MED index compares to traditional measures of wealth, the ward-level MED index is aggregated to the County-level and 
compared to a County-level GDP per capita (\$US 2005) proxy developed by the World Bank in 2015 that is built from nightlights data [4].

In Section 2 we review the existing demand and supply-side literature, as well as the literature that explores the relationship between the emergence of small businesses and wealth creation after initial electrification. In Section 3 we describe the data and methods used in this analysis, and Section 4 presents our results and provides a discussion. Section 5 concludes and provides a summary of the work, presents recommendations, and steps forward for future research.

\section{Background}

Most of the literature that investigates off-grid energy demand primarily focuses on the household. This focus has had a positive impact on the development of novel strategies through which many households in East Africa, and many other regions across the world, have received access to modern electricity services including pico power, solar home systems, and microgrids. Any single one of these strategies, however, is not a panacea for the problem of rural electrification as their longterm sustainability ultimately depends on the intertwined relationship between demand and supply, their fate in the context of their transitional nature, and the heretofore inexorable extension of the centralized grid. While the household has predominantly been a topic of interest for researchers, evidence from Kenya suggests that within rural communities, households could represent only 30\% of total electricity consumption, with institutions (schools, health care centers, and NGOs, for example) and micro-enterprises (retail and repair shops, agricultural processing, and hotels, among other services) representing the remaining $23 \%$ and $46 \%$ respectively [5]. Anecdotal evidence from microgrid developers, and personal communication with solar entrepreneurs has also shown that community-level demand-side concerns (estimating electricity demand potential and persistence accurately, and management) are some of the most immediate and pressing issues affecting the long-term business sustainability of off-grid solutions. In particular, and despite the widespread notion that electricity access can in and of itself ignite entrepreneurship potential (and in turn, increase electricity demand), there is very little research that explores the complementary infrastructure that can ignite that potential. Below we briefly summarize demand- and supply-side methodologies for off-grid electrification, as well as provide brief introduction to the literature that explores the electricity-entrepreneurship nexus with a particular focus on Kenya.

\subsection{Demand Side Literature}

Traditional approaches to off-grid electricity demand estimation, as well as those that evaluate users' ability and willingness to pay for electricity services, have traditionally used social science methods such as surveys [1][6], field and longitudinal studies [7][8], and stated preferences (contingent valuation, ability and willingness to pay) [9][10]. These approaches are extremely valuable as they usually provide detailed knowledge about a consumer and the intricacies of daily life in a region, village, or town. They can be used for evaluating the preference and decision making process that goes into buying and using different energy services (e.g., fuel wood or gas for cooking, kerosene or solar maps for lighting, for example), and perhaps later be used for better designing tariff structures, or demand side management schemes, among other things. However, although extremely insightful about a particular place, they are also time-consuming, and results are usually not generalizable.

Demand-side methodologies have also shed light into rural offgrid energy transitions at the household and village level, finding them to be better explained by 'energy stacking' or 'energy webs' (where households use different energy sources for the same or multiple purposes) rather than linear transitions [11][12][13]. In South Africa, research regarding appliance ownership and grid-electricity access and demand also demonstrated that ownership of electric appliances did not necessarily mean that they were used, or that if they were used, that they were powered by the grid (or in other places, by solar home systems)[8][14]. Take, for example, households that might buy appliances for their symbolic value in a mere attempt to conceal poverty, or on the other hand, the widespread use and preference of dry-cell batteries for powering radios [8][14].

Finally, 'end-use' approaches are less often used, but under the right assumptions, can be very useful for estimating a village or town's electricity demand. This methodology allows the researcher to incorporate different scenarios (behavioral dynamics, energy-efficient devices, and income and energy transitions, for example), and data sources (census and appliance ownership data, technology characteristics, and usage patterns, among others) to make assertions about electricity consumption in different economics sectors and areas of village life (household level, agricultural, and small commercial) [15][16]. Worth noting is that although many of these provide household and village estimates of appliance ownership and electricity demand, there has been little thought given to the topic of demand persistence, or long-term electricity demand potential. For many businesses and electricity providers in the energy access space, understanding long-term demand potential is crucial to ensuring growth in revenue and financial sustainability.

\subsection{Supply Side Literature}

Several studies have explored optimal supply-side approaches to electricity access in Kenya [17][18][19]. Many of these include using spatial least-cost optimization models to determine whether grid electrification (and expansion) or off-grid alternatives (solar PV and diesel mini-grids) are more suitable to the particular demand characteristics of rural Kenya [17][18]. Results from a one-scenario analysis (using fixed costs and electricity demand levels, varying penetration levels) of grid vs. off-grid alternatives in Kenya found that under most demand and geographic conditions, extension of the national grid would be less costly than off-grid options [17]. On the other hand, similar analyses that implemented several scenarios (high grid electricity costs, high PV efficiency, high demand, high/low diesel prices) have found that electrification strategies vary 
depending on the specific sub-local characteristics of a region [18]. For example, grid extension was found to be only suitable for grid cells featuring high demand and population density, whereas off-grid alternatives were more suitable for the often scattered populations of rural Kenya [18]. Recent work pushes back on several of these studies, suggesting that electricity access remain elusive not only in off-grid areas, but "under-grid" areas as well [3][9][20]. These studies demonstrate that even in "ideal settings" with high population density and extensive grid coverage, electrification rates (and possibly the benefits for electrification) for rural households and businesses remain very low, suggesting that investments in grid infrastructure in some places in Kenya have not translated to equally high rates of rural electrification, primarily because of the relative high cost for households and businesses to obtain a new connection [3][9][20]. Perhaps a reason why an 'optimal electrification strategy has remained elusive is due to the relatively little importance that electricity demand estimation has received in these analyses. Although these studies do take into account important proxies for electricity demand such as other household expenditures, education, poverty, population density and urban vs. rural differences, they often fail to mention or incorporate energy transition theories, complementary infrastructure (presence of roads and trade centers for example), and consumption preferences. In Kenya in particular it has been shown that the main driver of household rural electrification is not desire for electricity per se, but the desire for connective appliances (TVs, radios, and more recently cellphones) [7][13][21].

\subsection{Micro-Enterprises, Small Businesses, and Electricity}

Although outdated, Kenya's only survey (1999) on the country's diversity of small- and micro-enterprises provides valuable insight into the relationship between electricity access and entrepreneurship [5]. The survey highlights the great sectorial diversity of small (between 10 and 50 employees) and microenterprises (up to 10 employees) in rural areas, including trade $(65 \%$, predominantly agricultural), manufacturing $(15 \%)$, services $(12 \%)$, bars/hotels/restaurants $(6 \%)$, and construction $(2 \%)$. Of these, traders represented the largest population using electrified machines (51\%), followed by manufacturers $(20 \%)$, and services $(29 \%)$. At the time, rural micro-entrepreneurs reported that poor roads, access to markets, and lack of credit (access to finance) were some of their most severe constraints, with electricity not representing a major barrier, although only $33 \%$ of them had access to it. Similar results were found in South Africa [22][23], where absence of electricity only ranked $34^{\text {th }}$ out of 46 possible business problems in a micro-enterprise survey. In 2003, The World Bank published a large literature review and survey of productive uses of electricity in rural areas [24], and yet, it is not clear if off-grid entrepreneurs, and top-down energy planners incorporate this information into their decision making

Kenya's Lighting Africa 2008 assessment of off-grid rural smalland micro-enterprises also highlights the plethora of concerns faced by businesses [25]. It finds a predominantly agricultural population primarily concerned with improving their facilities $(55 \%)$, with only a few (11\%) thinking of electricity access as a top priority [25]. Within this subset, however, there is a clear understanding of the co-benefits of access, and how its use could be reflected in increased productivity and sales [25].

More recent research in Kenya highlights the complexity of the electricity-entrepreneurship nexus; elucidating that access is a necessary but not sufficient condition for the creation and development of rural micro-enterprises [6]. A 2006 study in the small town of Mpeketoni showed that access to electricity (availability and quality) significantly increased productivity per worker (quantity and quality of products) and revenues for micro-enterprises, as well as enabled mechanized agricultural processing and its co-benefits (increased sales, revenues, and trade) to flourish. However, the same article points out that electricity's catalyzing characteristics would not have been enabled without natural capital, markets, road infrastructure and facilities for social amenities (schools, polytechnics, and communication services); all which were developed prior to, or in parallel, with electricity access [6]. In combination, these surveys [5][22][23][25] and case studies [6][26][27] underscore the powerful synergy that exists between electricity access, human capital, and complementary infrastructure (schools, roads, and financial services, for example). With Kenya's population still being predominantly rural $(>75 \%)$, and off-grid electricity remaining limited (electricity access $<20 \%$ ), local dynamics and infrastructural synergies are crucial for understanding the viability of electricity access solutions.

Earlier studies in South Africa and India presented ample analysis and evidence to the range of social benefits (increased labor participation, time allocation for fuel collection, poverty reduction, and children's schooling), that can be derived from new connections and electricity access, but often ignored the conditions in which electricity access led to those outcomes [28][29]. However, more recent work in India and Kenya has begun casting doubt on the often-assumed causal link between electricity access and human development [30][31]. Work in India has compared nightlights data before and after the country's massive rural electrification program (2001 vs. 2011) with census data (demographics, occupational status, asset ownership, school enrollments and village level improvements) and found no evidence of human development outcomes improving over time [30]. The work in Kenya suggests that mass rural electrification through grid extension could have limited social welfare improvements, with electrification costs being at least four times higher than the ability and willingness to pay of households for new connections, and with consumer surplus appearing lower than total costs [31]. Although intriguing and suggesting alternative hypotheses, neither of these articles explore the conditions in which willingness to pay for electricity might be higher or lower, nor the diversity of conditions under which electricity can lead to improvements in human development, or the amount of time that must pass for electrification to have its greatest impact towards improving social well being and human development outcomes. We demonstrate in the following sections, what we consider are important data elements that need to be included in analysis of the benefits of electricity access. The same data and approach can be used by top town energy access planners and off-grid 
entrepreneurs to find new regions in which their services are likely to be impactful, profitable, and long lasting.

\section{Methods}

Our approach seeks to elucidate areas of high potential for micro-enterprise development in Kenya by using different proxy-variables for natural and infrastructural capital. We consider areas of high NC and IC to potentially have a high degree of electricity demand persistence, and thus could suggest a road map to guide off-grid entrepreneurs. The data suggests that natural capital is the foundation of wealth in rural Kenya, as access to it enables infrastructural capital to flourish. On the other hand, access to high quality infrastructure also allows communities and villages to increase the benefits they could derive from natural capital. Furthermore, and as the literature suggests, electricity access can under the right conditions act as a catalyst for off-grid communities to thrive. Below we describe the natural and infrastructural capital datasets used in our analysis, and provide a description of our exploratory spatial analysis and the development of an index that measures MicroEnterprise Development potential (MED).

\subsection{Data}

A summary of the data used in this study is available in Table 1. Nationwide geo-spatial data for rivers (current), small and largescale irrigation projects (historical and planned), crop diversity (average number of crops grown; 1997) and intensity (percent land under cultivation; 1997) were collected from the World Resources Institute (WRI), the International Livestock Research Institute (ILRI), and Kenya's National Irrigation Board [32][33][34]. We also use an agro-ecological potential score which is a composite index of moisture availability classification, rainfall $(\mathrm{mm})$, average annual potential evaporation ( $\mathrm{mm}$ ), vegetation, potential for plant growth assuming that soil conditions are not limiting, and risk of failure of an adapted maize crop [35][36]. The agro-ecological potential score is ranked from one (high potential: humid forest with high potential for plant growth and extremely low risk of failure of an adapted maize crop) to six (low potential: arid to very arid regions, bushland or desert scrub, with low potential for plant growth an and high failure for maize crops). As most rural populations are predominantly employed in agriculture, natural capital is crucial for their livelihood, a stable cash flow, and for providing the basis for agricultural processing activities. The combination of access to fertile soils and water is reflected in greater agricultural productivity, and year-round irrigation access (as opposed to rain fed agriculture) can translate into a more stable cash flow throughout the year.

Methods for measuring infrastructural capital include a wide diversity of variables mostly concerning distance to services and neighboring communities. Nationwide data for existing schools, health care centers, and trade centers throughout the country (electrified vs. non-electrified) were obtained from Kenya's Rural Electrification Authority (2014) [37], and geo-spatial data for major towns, $1^{\text {st }}$ and $2^{\text {nd }}$ tier roads, and transmission infrastructure were obtained from the WRI and ILRI.
Population density estimates were calculated using the highest resolution administrative unit for which data are available in Kenya (ward) for population and ward area $\left(\mathrm{km}^{2}\right)$ from the

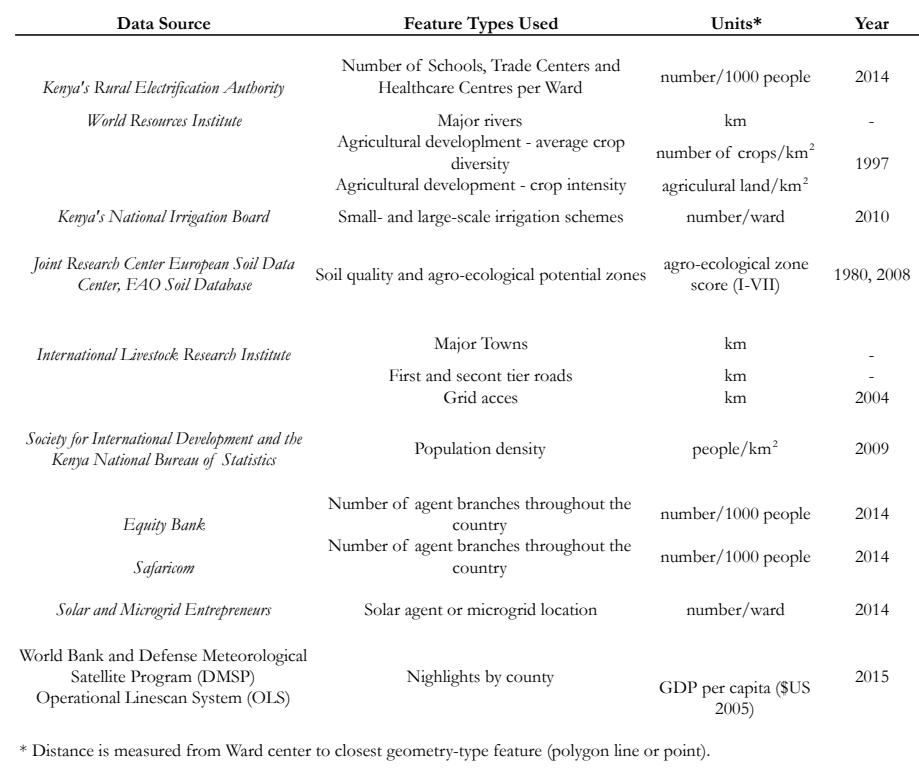

Table 1: Data Sources

Society for International Development and the Kenya National Bureau of Statistics (herein, "SID-KNBS") (2009). Data for spatial location of transmission lines, solar vendor shops and micro-grid locations were obtained for Kenya's Rural Electrification Authority, M-KOPA, Sun Transfer, SteamaCo, Powerhive, and the German Federal Ministry for Cooperation and Development. We include proxies for infrastructural capital because the literature suggests that social connectivity and education play a large role in unlocking the productive uses of electrification [13], and proximity to roads, major towns and trade centers allows for more vibrant local economies. Anecdotally, population density is one of the few variables that is used by access entrepreneurs to identify off grid target communities. We used the location of all Equity Bank and MPESA agents throughout the country (2014) as proxies for access to finance. Equity Bank is a financial services provider based in Nairobi with branches and an agent network that span almost everywhere in the country, and M-PESA is a mobilephone based money transfer and micro-financing service that is ubiquitous throughout Kenya. Users of M-PESA can deposit money into an account referenced to their phone SIM card, send balances using SMS to other users, and redeem cash deposits from M-PESA agents throughout the country. Equity Bank and M-PESA are distributed extensively throughout the country and provide both mobile money and, increasingly, loans (M-Shwari) to a wide diversity of populations, with $80 \%$ of Kenya's adult population being actively engaged with mobile money. Recent research from Kenya suggests that over the last decade M-PESA has increased per-capita consumption levels and lifted 194,000 households, or $2 \%$ of Kenyan households, out of poverty [38].

3.2 Exploratory Spatial Analysis and Index Development 
In our analysis, all geo-spatial calculations are performed with respect to the center of each of our highest resolution administrative units (wards). For polygon lines (rivers, $1^{\text {st }}$ and $2^{\text {nd }}$ tier roads, and transmission lines), distance ( $\mathrm{km})$ is calculated from the center of a ward to the closest point in a line. Distance $(\mathrm{km})$ from ward center to the closest major town (a 'geo-point') is also calculated, whereas for other 'geo-points', such as irrigation projects, we sum the total number of projects per ward. M-PESA and Equity Bank agents throughout the country are treated as geo-points and we sum their presence (agent branches/1000 people) by ward. Similarly, we also add the total number of schools, trade centers, and health care centers by ward (electrified vs. unelectrified; number/1000 people). We perform a geo-spatial merge using our ward and crop intensity and diversity geo-referenced data, resulting in a metric for wardlevel agricultural potential. Finally, when necessary, each variable is normalized between 0 and 1 using feature scaling, using the maximum and minimum of each value, and then summing across values. The result is a non-weighted microenterprise potential index ranging from 0 to 7 .

We explicitly compare the MED index between areas of high and low agro-ecological potential, and the MED index (and the natural and infrastructural capital) between wards with and without off-grid projects in areas across Kenya that do not have presence of electrified facilities (as for provided by the Kenya Rural Electricity Authority). We hypothesize that the MED index will score highly for places in Kenya that have already taken advantage of their natural and infrastructural capital, as well as for places that have yet to be fully developed. Thus, the MED index serves both as a tool to understand how development has occurred in a particular region or country (rich in natural and infrastructural capital), as well as a tool to map potential for wealth creation if more and better infrastructure were available (places with high natural capital but little infrastructural capital).

\section{Results and discussion}

Natural capital and infrastructural capital are well paired in Kenya, and one follows the other. The regions with highest agro-ecological potential also have some of the greatest crop diversity and intensity, and natural and infrastructural capital investments, making the land more productive, and in turn, more populated. High agro-ecological potential, if paired with year-round water availability (proximity to irrigation projects and rivers), may lead to increased crop diversity and intensity, which may lead to the creation of towns and the build up of infrastructural capital including trade centers, roads, electrification infrastructure and electrified facilities, and schools. This is visually explicit both from the subset of maps depicted to the right, and the data. On average, the regions with highest agro-ecological potential (composite agro-ecological index 1-4) have more natural capital infrastructure (four times more crop diversity, 35\% more land dedicated to agriculture, six times more irrigation projects), and infrastructural capital (twice the number of schools, clinic, and trade centers per thousand people, and four times the number of electrified schools, clinics, and trade centers per thousand people, and twice the number financial
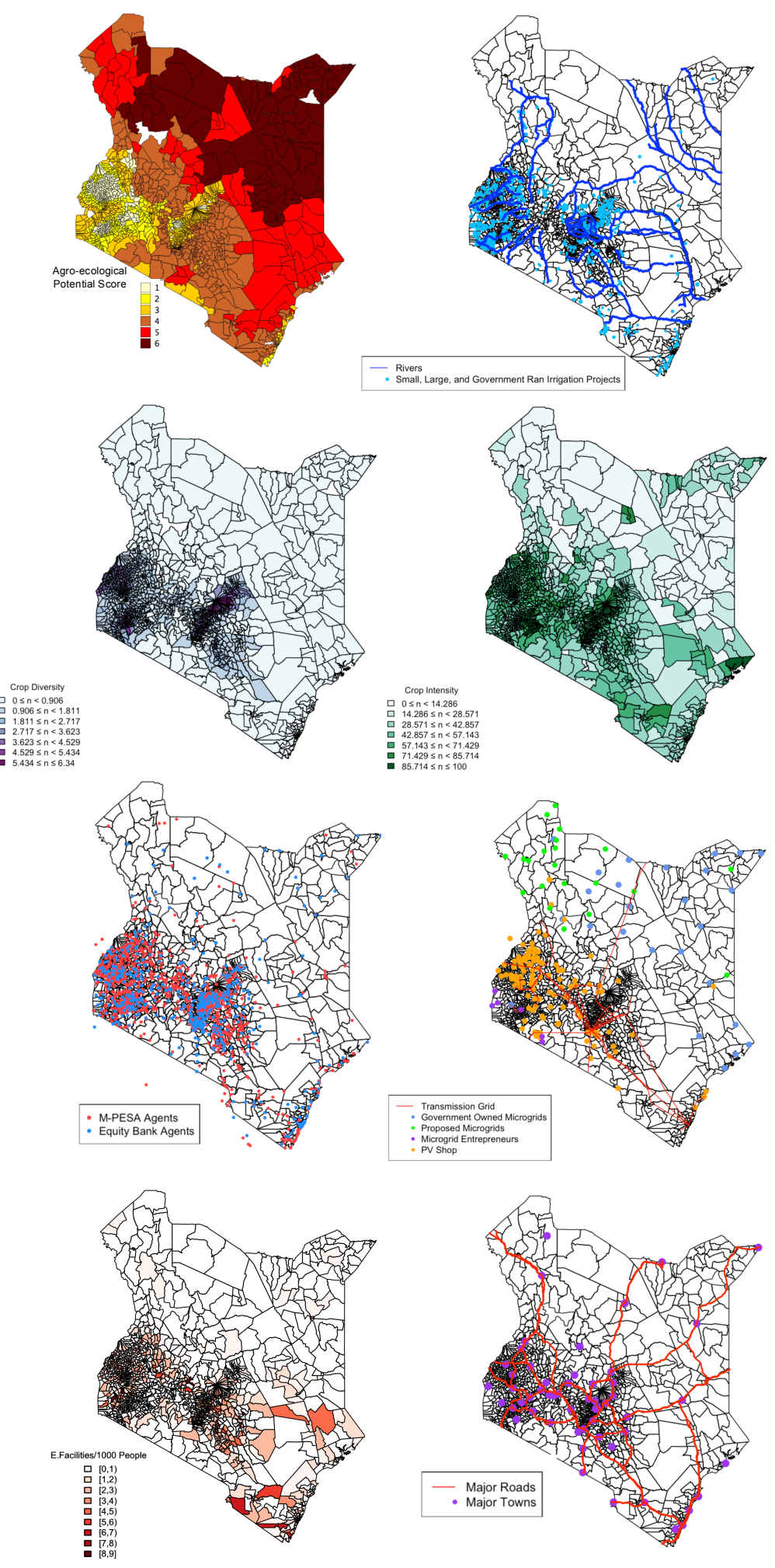

Figure 1: Natural and Infrastructural capital in Kenya (by Wards). Natural Capital includes: [A] Small and large irrigation projects as well as major rivers, [B] crop diversity, [C] crop Intensity, and [D] agro-ecological potential, among several other variables. Infrastructural capital includes [E] finance (M-Pesa and Equity Bank locations), [F] electrification infrastructure, $[\mathrm{G}]$ electrified facilities per 1000 people, and $[\mathrm{H}]$ major roads and towns, among several other variables. 
branch agents per thousand people) than areas in Kenya with low agro-ecological potential (composite agro-ecological index 5$6)$.

Although our off-grid projects database does not contain all offgrid electrification projects across the country, we are still able to compare the MED index of wards with available off-grid projects against the MED index of wards without off-grid projects and without presence of electrified facilities (as provided by the Kenya Rural Electricity Authority). On average, wards with off-grid electrification projects (government, entrepreneur and proposed microgrids, and solar home system branches) are located in areas of medium-high and medium-low agroecological potential (mean: 3.2, stddev: 1.7), with average crop intensity (47\% of land dedicated to agriculture, on average) and average crop diversity ( 2 crops, on average), and on average, are $4 \mathrm{~km}$ further away from rivers, and with double the number of irrigation projects than other wards in our data. In terms of infrastructural capital, off-grid wards have a slightly lower number of schools, health care clinics and trade centers facilities (8 per thousand people vs 11 per thousand people on average), a similar number of financial branches or agents per thousand people than the country average, and are almost twice as far away from major roads, towns, and transmission grid lines than other wards in our data. These results are not striking, as we have observed that the regions with higher natural capital to be more tightly correlated with higher investments in infrastructural capital. Consequently, off-grid electrification projects pursue opportunities in perhaps more remote regions. The average MED index of wards with presence of off-grid projects is 4 (out of 7), against the average MED countrywide index of 5 .

While these insights are not striking, we do find marked differences in natural and infrastructural capital between wards where entrepreneur-driven solar home system branches and entrepreneur microgrids operate versus wards where government-owned and government-proposed microgrid projects have settled.

On average, wards with entrepreneur operated off-grid electrification projects are located in areas of high to mediumhigh agro-ecological potential (mean: 2.7, stddev: 1.3), with high crop intensity ( $55 \%$ of land dedicated to agriculture) and average crop diversity ( 2 crops), and on average, are $7 \mathrm{~km}$ closer to rivers, and with double the number of irrigation projects than wards with government operated off-grid projects. Wards with entrepreneur operated off-grid electrification projects have a slightly lower number of schools, health care clinics and trade centers facilities ( 8 per thousand people vs 11 per thousand people), a lower number of electrified schools, clinics and trade center ( 4 per thousand people vs 7 per thousand people), a higher number of financial branches or agents per thousand people than the country average ( 5 per thousand people vs 3 per thousand people, respectively), and are equally as far away from major roads and towns, but further away from major transmission lines than wards with government operated off-grid projects. The MED index of wards with entrepreneur operated off-grid electrification projects is the same as the country countrywide index of 5 .
We compare the MED index scores to a GDP per capita County metric (\$US 2005) developed using nightlights by the World Bank in 2015 (Figure 2 A and B) [4]. The GDP per capita metric for Kenya uses nightlights as a proxy for economic activity, and assumes that consumption and investment activities in the evening or night require lighting. Nightlights are often used to estimate economic activity at levels that are not usually captured in national accounts, including subnational administrative units such as provinces, districts, counties, cities [4].

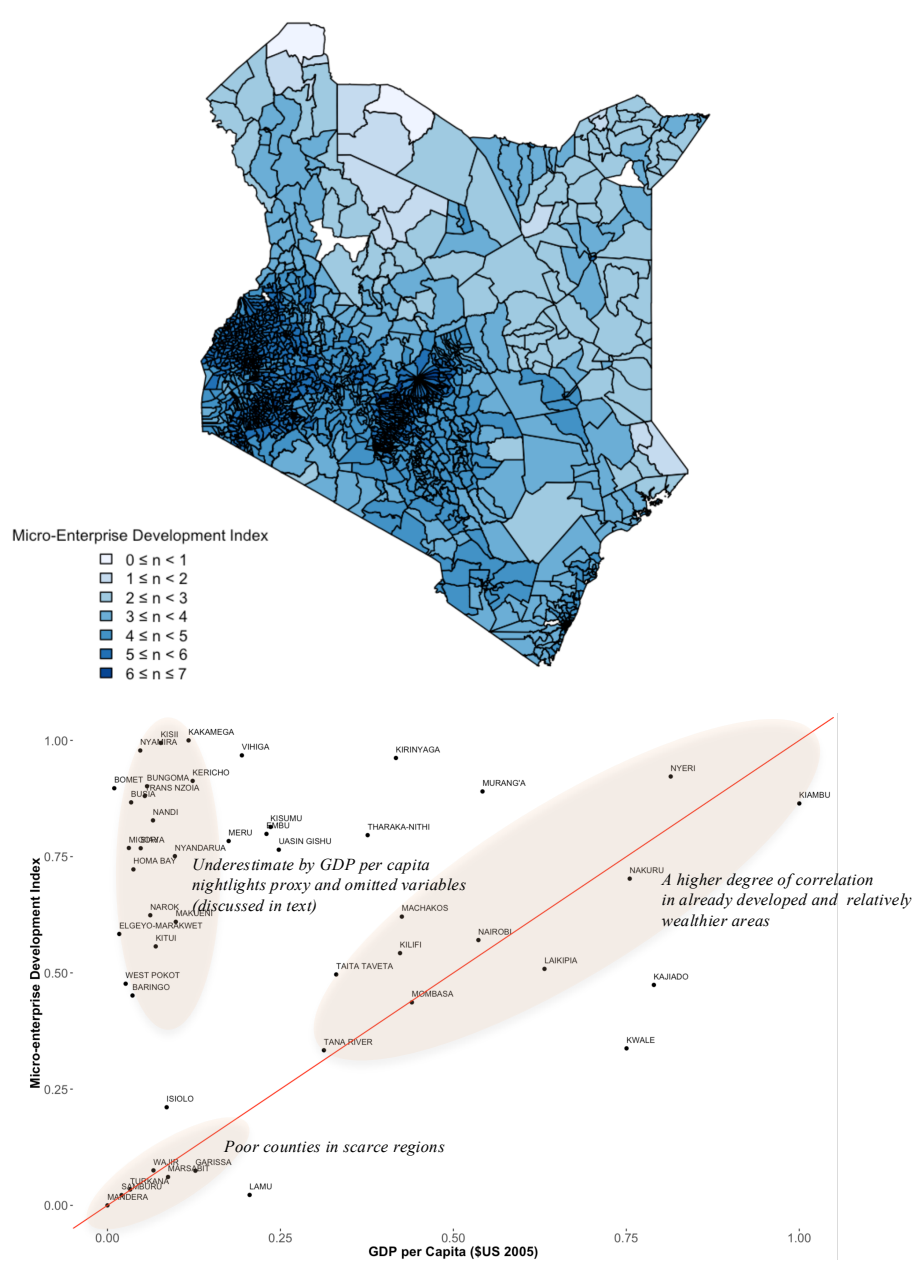

Figure 2: Micro-Enterprise Development Index [A] and Correlation with GDP per Capita nightlights proxy by County [B]: The MED index correlates well with the middle, and high-middle income regions of the country, as well as the poorest counties in the country. The MED index provides an overestimate for low-middle income counties (discussed below).

Although useful when no other data is available, using nightlights alone can lead to underestimates of economic activity, particularly in countries (and counties) that heavily rely on agriculture (including subsistence agriculture), herding, and other economic activity that predominantly occurs during the day. In countries like Kenya (including wards and counties), nightlights may not appropriately capture economic activities like livestock herding, farming, subsistence farming, and fishing. Yet, this proxy for GDP per capita was one of the few available to 
validate and provide a qualitative and quantitative comparison to our MED index.

To compare the ward-level MED index with the country-level GDP per capita nightlights proxy by the World Bank we took the MED index average of all wards within each County and scaled the scores between 0 and 1 using their minimum and maximum values. Similarly, the GDP per capita nightlights value was normalized between 0 and 1 using their minimum and maximum values. The MED index has a higher degree of correlation with the areas of Kenya with high, middle-high, and very low income, than with areas middle-low income. Within the first group, the MED index correlates well with the nightlights proxy for GDP per capita in central Kenya, the southeastern coast, and the southeastern border with Tanzania. Within the first group the MED index provides over estimates for counties like Murang'a, Tharaka-Nithi, and Kirinyaga, while providing underestimates for Kajiado and Kwale counties. The latter provide useful insights into data that could make the MED index more accurate. Kajiado County's most important economic activities include livestock rearing and tourism, with the popular Amboseli National Park being located there. Similarly, Kwale County's most important economic activities include beach tourism, fisheries and trade, with the first two being important omissions in our data set. Future work should include the diversity of local natural beauty and the health of fisheries and reefs to the importance of natural capital in a country. The natural capital wealth of the Murang'a, TharakaNithi, and Kirinyaga counties is reflected in the regional growth of cash crops such as coffee and tea, and yet, the difference between the MED index and GDP per capita proxy suggests a large gap between potential and realized wealth.

The MED index in very-low income counties is also well correlated with the GDP per capita proxy except for an underestimate in Lamu, which has a vibrant fishing and tourism industry (and thus the MED index providing an underestimate), and an overestimate for Isiolo. Isiolo is an interesting case as it is located in central Kenya and has become an important part of Kenya's economic development plan for 2030, despite it not being highly ranked in our MED index.

There are several reasons why the MED index noticeably provides an overestimate for many counties in the left-middle and upper-left corner of Figure 2-B. First, the data in the MED index are suggestive of the potential of a ward (and aggregated to counties) to derive socio-economic benefits from natural and infrastructural capital, and thus, it will necessarily attribute higher scores in regions that have high potential, but where infrastructural capital and wealth creation has yet to develop. Other reasons include the fact that the MED index has not been adjusted for climate stress factors (recurrence of droughts), population stress on available resources (deforestation, soil and land degradation, prevalence of unsustainable practices in agricultural expansion, unsustainable fishing practices, and over dependence on wood fuels), the quality of roads and services (not only a wards proximity to them), the health of local water bodies (pollution affecting lakes and fisheries), the local effects of climate change (drought, warming water bodies, and more variable precipitation), and the quality of local institutional governance, as corruption can be crippling to local economies. Recent research has also provided evidence to suggest that ethnic favoritism in Kenya can play a significant disadvantageous role in local development. Between 1963 and 2011, districts sharing the Kenyan president's ethnicity received twice as much expenditure on roads and five times the length of paved roads [39]. Furthermore, the comparison with the nightlights GDP per capita proxy is difficult, as the latter is likely an underestimate for the economic activity in many of these counties.

The MED index provides several other overestimates for counties such as Homa Bay, Nyandarua, Meru, Kisumu and Bomet. Homa Bay's most important economic activities include fishing and agriculture (including both staple and cash crops), agricultural processing in sugar cane factories, and lake tourism. Despite the presence of strong natural capital (fertile soils, water availability, and high crop diversity and intensity) and infrastructural capital, Homa Bay receives low GDP per capita estimates from the nightlights proxy, with a recent survey in Kenya putting Homa Bay in ninth position of the most corrupt counties in the country [40]. Nyandarua, Meru, Kisumu and Bomet also receive high MED index values in areas that grow both staple and cash crops, and have some industry and agricultural processing, but still receive low GDP per capita estimates from the nightlights proxy. Here, the dynamics are diverse and complex. Nyandarua County lacks a good road network and adequate distribution of electricity and water, Meru has high natural capital with fertile soils and water resources but most of the population is engaged in subsistence farming, and Bomet has favorable climatic conditions, fertile soil and water availability with tea farming and dairy production as favored economic activities, yet according to surveys, it is also the sixth most corrupt County in Kenya [40]. Kisumu County's privileged location next to Lake Victoria provides both water resources and fertile soils. Some have denominated it as the next economic hub of East Africa, but Lake Victoria's pollution levels, increasing water temperature due to climate change, overfishing and unsustainable (and illegal) fishing practices have devastated fisheries (Chinese fish now have to be imported to meet local demand) [41]. Nyamira, Kisii and Kakamega Counties provide the most startling comparisons as the MED index is one of the highest, and yet, the counties are poor according to the nightlights GDP per capita proxy. Nyamira and Kisii are highly agricultural productive neighboring counties (cash crops like tea and coffee, as well as staple crops), with fertile soils and water availability, but with little access to quality roads that provide access to markets, year-round irrigation, and reliable electric power that can allow for the flourishing of other industries in agricultural processing [42]. Furthermore, tea and coffee cooperatives in both counties are heavily burdened by debt, and the counties rank as the second and third most corrupt counties in the country [40][42]. Kakamega County stands alone in its contrasts, as in 2014 it was named the poorest County in the country, but has one of the highest MED index scores [43]. The County has similarly favorable agro-ecological potential and climatic conditions as Kisii and Nyamira, but its predominant agricultural activity is sugarcane. Once a booming industry, the sugarcane industry in Kakamega is now unsustainable due to 
small land holdings, low-yields, little efficiency in sugar production, and debt [44]. Moreover, farmers find themselves with minimal benefits from commercial sugarcane production after continuous laboring in the industry [45]. Cane farmers in Kakamega experience various deductions that reduce the benefit from their labor which includes high costs of transportation, harvesting, supervision, out growers' services, levies, land preparations, and input advances costs [45].

The agreements and differences in the information portrayed by the nightlights GDP per capita proxy and the MED index is informative towards the current local use of resources (agreeing on areas that have already been extensively developed, and where there is poverty and very little natural and infrastructural potential), and provides indication of areas where the gap between realized and achieved potential is large, as well as highlighting areas with merely unrealized potential. The data shows that the combination of many of the MED elements and electricity can lead to socially beneficial outcomes, and highlights once again, that electricity access is a necessary but not sufficient condition for development. Like our previous discussion suggests, a County may have optimal natural and infrastructural capital requirements but can remain poor due to poor governance and corruption, poor cash crop selection, unsustainable agricultural and fishing practices, as well as debt. While electricity access entrepreneurs cannot take on all these issues simultaneously, they can certainly incorporate practices that can lead to a sustainable business and socially beneficial outcomes. These could include partnering with organizations that work with farmers on financial management and accounting, cost-effective and sustainable farming practices and crop selection, and climate resilience, among others. Furthermore, the development of infrastructural capital is crucial with access to markets as well as availability of communications and financial services being extremely important factors.

\section{Conclusion}

This paper was written to begin developing an understanding of the enabling environments of entrepreneur vs. government run off-grid electrification projects, explore the role that $\mathrm{NC}$ and IC can play in determining wealth creation post-electrification, and attempt to develop a micro-enterprise development (MED) index that could be used to guide top-down energy planners and off-grid energy access entrepreneurs in Kenya. We gather data and use variables that are considered in the literature to provide appropriate conditions under which electrification can lead to long-term socially beneficial outcomes including access to roads, markets, schools, communications, and finance, as well as the natural capital that enables infrastructural capital to be transformative. The maps and data of Kenya show that natural and infrastructural capital are tied to each other, with their quality and health being essential to ensure the long term beneficial outcomes of electrification. Like our discussion suggests, electricity may allow certain industries in agricultural processing to flourish, and may allow fishing markets to buy refrigerators for cold storage, but unsustainable farming practices may deplete the soil, and unsustainable fishing practices, pollution, and warming water bodies may havoc fisheries. Natural and infrastructural capital may provide appropriate conditions for wealth creation, but ensuring the long-term benefits of electrification could depend on developing sustainable practices and good governance around the industries that may flourish post-electrification.

While the MED index highlights regions in a country where electrification could be most transformative, our discussion also suggests that there are many elements that are missing from our analysis. The health of fisheries, water body health (e.g., pollution, temperature, $\mathrm{pH}$ ), climate stress factors (recurrence of droughts), local choice of cash and staple crops, population stress on available resources (deforestation, soil and land degradation, prevalence of unsustainable practices in agricultural expansion, unsustainable fishing practices, and over dependence on wood fuels), the quality of roads and services (not only proximity to them), and the quality of institutional governance are but a few of the factors that can determine the long-term beneficial outcomes of electrification. Another missing data element from our analysis is ethnic favoritism, which in Kenya has shown to play a crucial role in development [39].

Top-down energy planners and off-grid energy access entrepreneurs could use this data and analysis to find areas with large untapped potential, and are encouraged to develop transformative alliances with NGOs, institutions, and other enterprises that provide sustainable solutions around natural and infrastructural capital. Our analysis and map suggest that there are many areas in Kenya with large untapped potential, and offgrid-entrepreneurs could find themselves well equipped to take advantage of this opportunity if they develop the locally appropriate transformative alliances. Knowing that electricity in and of itself cannot be fully transformational, developing alliances with groups that support sustainable farming and fishing practices, cost-effective transportation, co-ops and market access, and financial services could play a large role in ensuring the long-term socially beneficial outcomes that electricity access promises to provide.

\section{Acknowledgements}

The authors would like to thank the IBM-Africa research lab in Nairobi, under which most of this research was developed. Diego Ponce de Leon Barido acknowledges the CONACYTUCMEXUS fellowship, and the Link Energy Fellowship for supporting his work.

\section{References}

[1] United Nations Foundation. Microgrids for Rural Electrification : A critical review of best practices based on seven case studies. United Nations Sustinable Energy for All Practicioner Network (United Nations Foundation); 2013.

[2] P. Alstone, D. Gershenson, and D. M. Kammen, "Decentralized energy systems for clean electricity 
access," Nat. Clim. Chang. 2015; vol. 5, no. 2002, pp. 305-314.

[3] K. Lee, E. Brewer, C. Christiano, F. Meyo, E. Miguel, M. Podolsky, J. Rosa, and C. Wolfram, "Electrification for 'under Grid' households in Rural Kenya," Dev. Eng. 2016; vol. 1, pp. 26-35.

[4] T. Bundervoet, L. Maiyo, and A. Sanghi. Bright Lights, Big Cities : Measuring National and Subnational Economic Growth in Africa from Outer Space, with an Application to Kenya and Rwanda. World Bank; 2015.

[5] UNDP. National Micro and Small Enterprise Baseline Survey, Kenya (United Nations Development Programme); 1999.

[6] C. Kirubi, A. Jacobson, D. M. Kammen, and A. Mills. Community-Based Electric Micro-Grids Can Contribute to Rural Development: Evidence from Kenya. World Dev (2009); vol. 37, no. 7, pp. 1208-1221.

[7] P. Alstone, K. Radecsky, A. Jacobson, and E. Mills. Field Study Methods and Results from a Market Trial of LED Lighting for Night Market Vendos in Rural Kenya. Light \& Engineering 2013; vol. 22, no. 2, pp. 23-37.

[8] C. Thom,Use of grid electricity by rural households in South Africa. Energy Sustain Dev 2000; vol. 4, no. 4, pp. 36-43.

[9] S. Abdullah and P. W. Jeanty. Demand for Electricity Connection in Rural Areas: The Case of Kenya. University of Bath, Bath Economics Research Papers. 2009.

[10] ESMAP - World Bank. A New Slant on Slopes Measuring the Benefits of Increased Electricity Access in Developing Countries. 2010.

[11] M. Madubansi and C. M. Shackleton. Changing energy profiles and consumption patterns following electrification in five rural villages, South Africa. Energy Policy 2006. vol. 34, no. 18, pp. 4081-4092.

[12] O. R. Masera, B. D. Saatkamp, and D. M. Kammen. From linear fuel switching to multiple cooking strategies: A critique and alternative to the energy ladder model. World Dev 2000; vol. 28, no. 12, pp. 2083-2103.

[13] A. Jacobson. Connective Power: Solar Electrification and Social Change in Kenya. World Dev. 2007, vol. 35, no. 1, pp. 144-162.

[14] M. Davis. Rural household energy consumption. Energy Policy 1998; vol. 26, no. 3, pp. 207-217.
[15] A. Banerjee, Rangan, Pandey, Ranhul, Bhure. Electricity Demand Estimation for Village Electrification. Rep. Indian Inst. Technol. Bombay, 2006. White Paper.

[16] D. Fabini, D. Ponce, D. L. Baridó, A. Omu, and J. Taneja. Mapping Induced Residential Demand for Electricity in Kenya. ACM DEV -5 '14 Proc. Fifth ACM Symp. Comput. Dev., vol. 5, pp. 43-52, 2014.

[17] L. Parshall, D. Pillai, S. Mohan, A. Sanoh, and V. Modi. National electricity planning in settings with low preexisting grid coverage: Development of a spatial model and case study of Kenya. Energy Policy 2009; vol. 37, no. 6, pp. 2395-2410.

[18] M. Zeyringer, S. Pachauri, E. Schmid, J. Schmidt, E. Worrell, and U. B. Morawetz. Analyzing grid extension and stand-alone photovoltaic systems for the costeffective electrification of Kenya. Energy Sustain. Dev., 2015; vol. 25, pp. 75-86.

[19] S. Szabó, K. Bódis, T. Huld, and M. Moner-Girona. Sustainable energy planning: Leapfrogging the energy poverty gap in Africa. Renew. Sustain. Energy Rev 2013. vol. 28 , pp. 500-509.

[20] S. Abdullah and A. Markandya, "Rural Electrification Programmes in Kenya: Policy Conclusion from a Valuation Study," World Bank Rep., pp. 1-38, 2009.

[21] E. Alstone, Peter, Radecsky, Kristen, Jacobson, Arne, Mills. The Dynamics of Off-grid Lighting Adoption: Field Study Methods and Results from a 2008-2009 Market Trial of Night Market Vendors in Rural Kenya. Lawrence Berkeley National Lab. 2009.

[22] C. M. Rogerson. The Market Development Approach to SMME Development: Implications for Local Government in South Africa. Urban Forum 2006; vol. 17, no. 1, pp. 54-78.

[23] C. M. Rogerson and Southern African Migration Project. International migration, immigrant entrepreneurs and South Africa's small enterprise economy. Migr. policy Ser. 1997; ; no. 3., p. 22.

[24] World Bank. Survey of Productive Uses of Electricity in Rural Areas. 2003.

[25] International Finance Corporation. Lighting Africa Market Assessment Results Quantitative Assessment Kenya. Lighting Africa Program. 2008.

[26] G. Naituli, F. N. Wegulo, and B. Kaimenyi.

Entrepreneurial characteristics among micro and smallscale Women owned enterprises in North and Central 
Meru districts, Kenya. Glob. Imaging Mark. Conf. Delhouse 1 Univ. Nov. Scotia, Canada 20th to 24th June 2008., no. June 2008, pp. 1-19, 2008.

[27] IFAD. Financing Smallholder Farmers and Rural Entrepreneurs in the Near East and North Africa. International Fund for Agricultural Development. 2011.

[28] World Bank. Who Benefits Most from Rural Electrification? Evidence in India. Policy Research Working Papers. 2014.

[29] T. Dinkelman. The effects of rural electrification on employment: New evidence from South Africa. Am. Econ. Rev 2011. vol. 101, no. 7, pp. 3078-3108.

[30] F. Burlig and L. Preonas. Out of the Darkness and Into the Light? Development Effects of Rural Electrification in India. Energy Institute at HAAS. Working Paper 268. 2016.

[31] K. Lee, E. Miguel, and C. Wolfram. Experimental Evidence on the Demand for and Costs of Rural Electrification. NBER Work. Pap. Ser. 2016; no. 22292.

[32] World Resources Institute. Kenya GIS Data Resources 2013. Available from:

(http://www.wri.org/resources/data-sets/kenya-gisdata) [Last accessed December 2013]

[33] International Livestock Research Institute. 2013. Available from: (https://www.ilri.org/kenya) [Last accessed December 2013]

[34] Kenya National Irrigation Board. 2013. Avaliable from: (https://www.nib.or.ke/) [Last accessed December 2013]

[35] Joint Research Centre European Soil Data Centre. 2013. Available from: (http://esdac.jrc.ec.europa.eu/content/agro-climaticzone-map-kenya-appendix-2-report-no-e1). [Last accessed December 2013]

[36] Food and Agriculture. Food and Agriculture Agricultural Zones. 2013. Available from: (http://www.infonetbiovision.org/EnvironmentalHealth/AEZs-FAOSystem). [Last accessed December 2013]
[37] Kenya Rural Electrification Authroity. 2013. Available from: (http://www.rea.co.ke/). [Last accessed December 2013]

[38] T. Suri and W. Jack. The long-run poverty and gender impacts of mobile money. Science 2016. vol. 354, no. 6317, pp. 4-9.

[39] R. Burgess, R. Jedwab, E. Miguel, A. Morjaria, and G. Padro i Miquel. The Value of Democracy: Evidence from Road-Building in Kenya. Am. Econ. Rev. 2015. vol. 105, no. 6, pp. 1817-1851.

[40] Kenya Today. List of top ten most corrup counties. 2016. Available from: (http://www.kenyatoday.com/facing-justice/list-top-ten-corrupt-counties). [Last accessed 2016].

[41] Mother Jones. One of the World's Biggest Lakes Is Dying and We're to Blame. 2015. (Available from: http://www.motherjones.com/environment/2015/01/ climate-change-lake-victoria-overfishing). [Last accessed 2016]

[42] Business Daily Kenya. Government invests in key projects to boost economy of Kisii, Nyamira counties. 2016. (Available from:

http://www.businessdailyafrica.com/projects-to-boosteconomy-of-Kisii--Nyamira-counties//539444/3196646/-/13beavj/-/index.html). [Last accessed 2016]

[43] Daily Nation. Kakamega the poorest county in Kenya. 2014. (Available from: http://www.nation.co.ke/counties/Kakamega-PovertyDevolution-Ministry-Report/1107872-251795630hd8t/index.html). [Last accessed 2016]

[44] Standard Media. Farmers in Kenya uproot sugarcane over dwindling fortunes. 2015. (Available from: https://www.standardmedia.co.ke/article/2000173963/ farmers-in-kenya-uproot-sugarcane-over-dwindlingfortunes). [Last accessed 2016].

[45] M. M. Duncan. Unsustainable Finances of the Sugar Economy in Kakamega County, Kenya. Int. Jrnl. Humn Soc. Sc. 2015. vol. 5, no. 11, pp. 133-138. 